\title{
Acoustic individuality in the hissing calls of the male black grouse (Lyrurus tetrix)
}

\author{
Lucie Hambálková ${ }^{\text {Corresp., } 1}$, Richard Policht ${ }^{1}$, Jiří Horák ${ }^{1}$, Vlastimil Hart ${ }^{1}$ \\ ${ }^{1}$ Department of Game Management and Wildlife Biology, Faculty of Forestry and Wood Sciences, Czech University of Life Sciences, Prague, Czech \\ Republic \\ Corresponding Author: Lucie Hambálková \\ Email address: hambalkoval@fld.czu.cz
}

Acoustic individuality may well play a big role during the mating season of many birds. Black grouse (Lyrurus tetrix) produces two different long-distance calls during mating on leks: rookooing and hissing calls. The first one represents low frequency series of bubbling sounds and the second one represents hissing sound. This hissing represents a signal not produced by the syrinx. We analyzed 426 hissing calls from 24 individuals in Finland and Scotland. We conducted cross-validated discrimination analyses (DFA). The discrimination model classified each call with almost $78 \%$ accuracy (conventional result) and the validated DFA revealed $71 \%$ output, that is much higher than classification by chance (4 $\%)$. The most important variables were Frequency $95 \%$, 1st Quartile Frequency, Aggregate Entropy and Duration $90 \%$. We confirmed that hissing call of black grouse is individually distinct. In comparison to the signals produced by the syrinx, non-vocal sounds have been studied rarely and according to our knowledge, this is the second evidence of vocal individuality in avian hissing sounds which are not produced by syrinx. Individuality in the vocalization of the male black grouse may aid females in mating partner selection, and for males it may enable competitor recognition and assessment. Individually distinct hissing calls could be of possible use to monitor individuals on leks. Such a method could overcome problems during traditional monitoring methods of this species, when one individual can be counted multiple times, because catching and traditional marking is problematic in this species. 
1 Acoustic individuality in the hissing calls of the male black grouse

2 (Lyrurus tetrix)

3

4 Lucie Hambálková1 ${ }^{*}$, Richard Policht ${ }^{1}$, Jiří Horák ${ }^{1}$, Vlastimil Hart ${ }^{1}$

5

6 'Department of Game Management and Wildlife Biology, Faculty of Forestry and Wood

$7 \quad$ Sciences, Czech University of Life Sciences

8 Kamýcká 129, 16500 Prague 6

9 Czech Republic

10

$11{ }^{*}$ Corresponding Author:

12 Lucie Hambálková

13 Kamýcká 129, Prague 6, 165 00, Czech Republic

14 Email address: hambalkoval@fld.czu.cz 


\section{ABSTRACT}

Acoustic individuality may well play a big role during the mating season of many birds.

Black grouse (Lyrurus tetrix) produces two different long-distance calls during mating on leks: rookooing and hissing calls. The first one represents low frequency series of bubbling sounds and the second one represents hissing sound. This hissing represents a signal not produced by the syrinx. We analyzed 426 hissing calls from 24 individuals in Finland and Scotland. We conducted cross-validated discrimination analyses (DFA). The discrimination model classified each call with almost $78 \%$ accuracy (conventional result) and the validated DFA revealed $71 \%$ output, that is much higher than classification by chance (4\%). The most important variables were Frequency 95 \%, 1st Quartile Frequency, Aggregate Entropy and Duration 90 \%. We confirmed that hissing call of black grouse is individually distinct. In comparison to the signals produced by the syrinx, non-vocal sounds have been studied rarely and according to our knowledge, this is the second evidence of vocal individuality in avian hissing sounds which are not produced by syrinx. Individuality in the vocalization of the male black grouse may aid females in mating partner selection, and for males it may enable competitor recognition and assessment. Individually distinct hissing calls could be of possible use to monitor individuals on leks. Such a method could overcome problems during traditional monitoring methods of this species, when one individual can be counted multiple times, because catching 44 and traditional marking is problematic in this species.

\section{INTRODUCTION}


47 At the time of a decline in the black grouse (Lyrurus tetrix) population across its distribution

48

49

50

51

52

53

54

55 range (Ciach 2015; Jankovska et al. 2012; Kasprzykowski 2002), determining actual number of individuals is becoming increasingly important. The causes for this decline vary: change of the environment and climate (Kurhinen et al. 2009; Kvasnes et al. 2010; Viterbi et al. 2015; White et al. 2013), parasite infestation (Jankovska et al. 2012), predation (Charnov et al. 1976; Korpimaki et al. 1996; Pekkola et al. 2014; Policht et al. 2019; Summers et al. 2004; Tornberg et al. 2013;

Widen et al. 1987), reducing genetic diversity (Segelbacher et al. 2003; Segelbacher et al. 2014) and human activities (Formenti et al. 2012; Hess \& Beck 2012; Ingold 2005; Nichter et al. 2017;

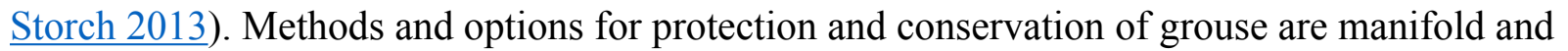
are realized at the local, regional, and national levels (Storch 2013).

An integral part of any conservation measures in general, and thus also in the case of black grouse populations in particular, is monitoring. Methods of monitoring are diverse.

Franceschi et al. (2014) simulated two monitoring approaches: plot sampling and distance sampling. According to their study, distance sampling is a better way to monitor grouse in terms of accuracy. On the other hand, this approach is also costly, as it requires 4-5 sampling points per $\mathrm{km}^{2}$ for reliable outcomes (Franceschi et al. 2014). The most common counting method for black grouse is to register males displaying in the spring (Hancock et al. 1999). Depending on the size of the area to be monitored, it is possible to perform a full-area survey or to select sample areas at random (Hancock et al. 1999). Monitoring based on acoustic features of bird vocalization could be a more efficient method. Laiolo et al. (2007) recommended combining counting based on vocalization with physical marking. Black grouse males produce the following kinds of sounds: resonant rookooing call and hissing calls. The latter is further subdivided into tones of aggression and alarm calls (Cramp 
70 1983). This study is focused on a particular type of hissing call - crowing-hiss, described by

71 Cramp (1983) as harsh and angry sound, which is produced during the display of male black

72 grouse. This hissing sound is not produced by syrinx. Such non-vocal sounds are produced by

73 some constriction located on the way from the lungs to the bill (Fitch \& Hauser 2003). Potential

74 information encoded in non-vocal sounds of birds remains almost unstudied (Budka et al. 2018).

75 Recent research of hissing sounds produced by geese confirmed encoding of individual identity

76 during antipredator behavior (Policht et al. 2020). In comparison to non-vocal acoustic signals of

77 birds, majority of bioacoustic studies focused on research of sounds produced by syrinx. A

78 hissing sound also appears in black grouse chicks above the age of three weeks, but we do not suppose it is the same sound category that is the focus of our study (Meinert \& Bergmann 1983).

80 This type of vocalization, along with the rookooing call, is the most prominent sound made by black grouse, which can be heard over long distances and even in closed habitats such as forests

82 with dense undergrowth. Such calls are frequently used for population monitoring to find actually used leks and counting present males. Therefore, this type of call may play an important role in noninvasive monitoring of black grouse. The rookooing call can be characterized as a

85 low-frequency, repetitive sound within a range of about $200 \mathrm{~Hz}$ to $1000 \mathrm{~Hz}$. This is why this type of call often overlaps with background noise frequencies. Compared with this, the hissing call is

87 found in the frequency range of $350 \mathrm{~Hz}$ to $4500 \mathrm{~Hz}$ and is therefore easier to filter out from background noise and to mark this type of call for measurement using acoustic software. Thanks to these characteristics, the hissing call may be more suitable for acoustic monitoring of black grouse.

In an effort to ensure quiet conditions for game wildlife, non-invasive monitoring, such as that based on vocalization, is the method of choice. This method relies on distinguishing 
93 individuals without physical marking. In our study, we analyzed the vocalization of male black

94 grouse to examine variation between individuals, and to find out whether vocalization

95 characteristics could serve as a unique identifying trait.

96

\section{METHODS}

98 Study Areas and Recording

99 We recorded the hissing calls of male black grouse during their mating season. Recording took 100 place in Finland in 2012 and 2013, and in Cairngorms National Park, Scotland in 2019. Field 101 experiments were approved by the Department of Natural Resources, Ministry of Agriculture 102 and Forestry, Finland and by the Game \& Wildlife Conservation Trust, Scotland. According to 103 Finnish legislation in general and to the hunting legislation, this type of scientific project does 104 not require any special permits or licenses. All appropriate permissions were in place for the 105 fieldwork in Scotland. The research was conducted in accordance with the guidelines of the 106 Animal Behavior Society for the ethical use of animals in research. The study was carried out in 107 accordance with the recommendations in the Guide for Care and Use of Animals of the Czech 108 University of Life Sciences, Prague. The Animal Care and Use Committee of the Czech Ministry of the Environment approved the protocol (Permit number: 15106/ENV/14-825/630/14).

110 Vocalization of male black grouse was recorded with the audio recorder Olympus LP-100 in 111 combination with a Sennheiser ME 66 directional microphone (frequency response $20 \mathrm{~Hz}-20$

$112 \mathrm{kHz} \pm 2.5 \mathrm{~dB}$ ) complemented by a K6 powering module. Recordings were saved in .wav format 113 (48 kHz sampling rate, 16-bit sample size). We recorded all individuals in the wild during 114 courtship at leks. Lek is an area where two or more males perform courtship displays to gain an 115 advantage for mating with females. All leks were approached before the arrival of males, about 
116 two hours before sunrise. Each recording session took on average one hour and was performed

117 from a portable hide so that the males could be observed without being disturbed. The distance

118 of the hide from display sites was $10 \mathrm{~m}$ on average. To avoid repeated recordings of the same

119 individual, only one recording from each location was included in the analysis. During the pilot

120 study, we only tested the variability between multiple individuals on one lek, and it turned out

121 that the individual variability is much larger. To avoid the risk of multiple counting of the same

122 individual, we chose the option of selecting only one, maximum of two individuals on each lek.

123 The distance between visited display sites was at least one kilometer and, according to Borecha

124 et al. (2017), black grouse males show strong fidelity to their lek; therefore, the risk of recording

125 the same individual at the two display sites was low.

\section{Acoustic Analyses}

128 Recordings were analyzed using Raven Pro 1.5 software with a 512 sample size and a Hann 129 window. We selected good quality calls with high signal to noise ratio, non-overlapping with 130 other hissing calls or background noise and wind. Each selected hissing call was manually

131 bounded by the selection frame that is defined by the beginning and end of the signal and the

132 lower and highest frequency of the signal. Temporal and frequency variables were then measured 133 automatically. These measurements were entered into the statistical analysis.

\section{Statistical Analyses}

136 We analyzed 426 good-quality calls from 31 individuals (at least 10 separate hissing calls per

137 individual). We measured 29 variables (Table 1). We excluded variables with low or no

138 variation. The remaining variables were standardized using Z-score transformation (subtracting 
139 the mean and dividing by standard deviation). In order to test individual variation, we used

140 stepwise Discrimination Function Analysis (DFA) using IBM SPSS Statistics 24.0 software

141 (IBM Corp., Armonk, USA). We applied a leave-one-out cross-validation procedure (IBM SPSS

142 Statistics 20) to validate the results of DFA.

143 To test the potential for individual variation (Potential of Individual Coding - PIC) for each

144 parameter, we compared the coefficient of variation (CV) within and between individuals. The

145 PIC ratio was computed for each acoustic parameter by dividing the CVbetween by the mean of

146 the CVintra values related to each individual (Robisson 1992). For these tested parameters, a PIC

147 value greater than 1 means that an inter-individual variability is higher than intraindividual

148 variability. We tested a significance using Kruskal-Wallis test.

\section{RESULTS}

\section{Hissing Call Description}

152 The hissing calls of black grouse represent wideband acoustic signals, in which energy is spread

153 across a wide frequency range. The duration of such calls ranged from 0.1 to $1.21 \mathrm{~s}(0.76 \pm 0.16$,

154 mean \pm SD). This type of call can consist of 1 or 2 notes; however, the occurrence of a two-

155 syllable form was rare $(\sim \mathrm{n}<1 \%)$ - so we did not analyze these calls.

156 The Low frequency ranged from 352.9 to $1310.3 \mathrm{~Hz}(830.2 \pm 195.6 \mathrm{~Hz}$, mean \pm SD) and

157 the High frequency from 1702.4 to $4482.8 \mathrm{~Hz}(2687.5 \pm 536.4 \mathrm{~Hz}$, mean \pm SD) for all

158 individuals. The frequency ranged from 729.6 to $3241.4 \mathrm{~Hz}(1857.3 \pm 478.6 \mathrm{~Hz}, \mathrm{mean} \pm \mathrm{SD})$.

159 The spectrograms of black grouse recorded in Finland and Scotland are shown in the figures

160 below (Fig. 1,2). The spectrograms were generated in Avisoft-SASLab Pro with FFT length,

1611024 sample size, a Hamming window and $87.5 \%$ overlap. For a representative recording of a 
162 hissing call of one individual form Scotland and one individual from Finland see Audio S1 and 163 Audio $S 2$.

164

165

Individual Variation

166 From selected parameters the resulting model (see Supp. Table S1) included 13 significant

167 acoustic variables ( $\mathrm{p}<0.001 ; \mathrm{r} \leq 0.87)$ : $1^{\text {st }}$ Quartile Frequency, Relative $1^{\text {st }}$ Quartile Frequency, 168 Aggregate Entropy, Average Entropy, Relative Center Time, Call Duration, Duration 90 \%, 169 Frequency $5 \%$, Relative $3^{\text {rd }}$ Quartile Frequency, Frequency 95 \%, Inter-Quartile Range 170 Bandwidth, Inter-Quartile Range Duration and Time $5 \%$ (Table 1). The first 4 discriminant 171 functions had Eigenvalues $>1$ and explained $79.7 \%$ of the variation. With the first 172 discrimination function mostly correlated F95 \% (Frequency 95\%) (r=0.767) and Q1F 173 (Quartile 1 Frequency) $(\mathrm{r}=0.707)$ and the second discriminant function correlated best with 174 AggEnt (Aggregate Entropy) ( $\mathrm{r}=0.390)$ and Dur 90\% (Duration $90 \%)(\mathrm{r}=0.387)$ (Fig. 3). The 175 Discriminant Function Analysis excluded seven out of 31 individuals due to their missing or extreme values of the measured parameters. The cause could be a poorer degree of sound quality 177 that did not pass the analysis. This selection has been made by model procedure automatically.

178 The resulting DFA model correctly classified $77.9 \%$ (71.1\%, cross-validated result) hissing 179 calls. Six individuals showed the highest classification accuracy (80-100\%), and most 180 individuals $(\mathrm{N}=15)$ were classified with 60-79\% success. Only three males were classified 181 with a lower than $59 \%$ success. These results were much higher than classification by chance (4 182 \%). The output of classification results is shown in Supp. Table S2. We tested whether observed classifications differed from the expected classifications (by chance) and we found a significant 184 difference: Chi-Square $=307.1, \mathrm{df}=23, \mathrm{p}<0.001$. We also tested whether between individual 
185 variation is higher than within individual variation using PIC and we found that all acoustic

186 parameters had PIC > 1 (Table 2).

187

188

189

190

191

192

193

194

195

196

197

198

199

200

201

202

203

204

205

206

\section{DISCUSSION}

Our results reveal that the wideband hissing call of male black grouse is individual specific. The discrimination model classified each call with almost $78 \%$ accuracy, and the first 4 discriminant functions explained nearly $80 \%$ of variation. The PIC ratio was higher than 1 for all parameters tested, demonstrating that the variability between individuals was higher than the variability within individuals. Therefore, the hissing call is a type of vocalization that carries information about individuality. Considering this type of call is a wideband, non-vocal sound, such a result is quite unique. There are not many studies focused on non-vocal animal sounds and even fewer of them have provided results confirming individuality in this type of vocalization, but there are a few. Individual variation was found in the male Houbara Bustard (Chlamydotis undulata undulata), which produces sounds called booms during courtship (Cornec et al. 2014). Acoustic variation between individuals was also investigated in the Greater Prairie-chicken (Tympanuchus cupido) and the boom vocalization of this species was found to have individual characteristics (Hale et al. 2014). Thanks to temporal patterns, along with the number of drumming strokes, it is possible to discriminate individuals of the Great Spotted Woodpecker (Dendrocopos major) (Budka et al. 2018). According to acoustic analysis in the male Greater Sage-grouse (Centrocercus urophasianus), the "rustling" of wings differs between individuals (och et al. 2015). Therefore, mechanical sounds can also carry acoustic information about individuality. 

colonial birds or nocturnal birds. On the other hand, gallinaceous species has not been studied characterized by a potential for vocal individuality in terms of temporal parameters. Spectral characteristics of the voice are then associated with the possibility of greater stability during the development of the individual, which is important in the question of long-term recognition of individuals (Sezer \& Tekelioglu 2010). Call analyses of European and Japanese quail (Coturnix c. japonica, C. c. coturnix) confirm a difference between these two subspecies based on the time structure of vocalization (Collins \& Goldsmith 1998). The hazel grouse (Bonasa bonasia), studied in Switzerland, exhibits 6 to 11 elements of singing during flight. These elements

217 (individual tones or syllables) are characterized by their individual specificity (Mulhauser \& in males and females of the common quail (Coturnix coturnix); the results of this study also indicated that the male's inter-individuality is dependent on sexual maturation and age (Guyomarc'h et al. 1998). Our study demonstrates a vocal individuality in gallinaceous species with lek mating system. future research. Calls of individual birds may carry information about male quality (e. g., physiological state, age) for females (Guyomarc'h et al. 1998), and, at the same time, it might be a signal for other males providing information about the strength of a rival. Finally, individuality can serve to easily identify individuals among each other within a group. Its potential for scientists lies in the possibility of use for noninvasive monitoring. Taking an observation, census may be inaccurate; due to overflights of individuals within the lekking site, repeated census of 
230 the same individuals may occur and therefore the results of counting may be overestimated.

231 Monitoring based on acoustic recognition could provide the required accuracy and assistance in

232 areas where observation is limited by environmental conditions (e. g., the situation when males

233 of black grouse lek individually hidden in the undergrowth).

234

\section{Conclusion}

236 The black grouse population is affected by many factors that contribute to its decline, and as part

237 of its conservation, efforts are being made to develop better methods of protection, including

238 monitoring. Vocalization recording and analysis could be a non-invasive monitoring tool,

239 especially if there is individuality in the voice of individuals. This method could significantly

240 reduce the risk of multiple counting of the same individual. Surprisingly, we found this

241 individuality in the black grouse in the non-vocal type of display. The discrimination model

242 classified each call with high accuracy and important variables turned out to be Frequency $95 \%$

243 and Quartile 1 Frequency. In comparison to the signals produced by the syrinx, non-vocal sounds

244 have been studied rarely and according to our knowledge, this is the second evidence of vocal

245 individuality in avian hissing sounds which are not produced by syrinx. Finding specific

246 identifiers in vocalization could lead to a more accurate determination of the number of

247 individuals.

248

\section{Acknowledgements}

250 We very much appreciate the help and support of Mr. Christian Krogell, Department of Natural

251 Resources, Ministry of Agriculture and Forestry, Finland. We are also thankful to Mr. Ilkka Ala-

252 Ajos for logistical support for our research in Finland. Furthermore, we would like to thank Dr. 
253 David Parish, Marlies Nicolai and Dr. Kathy Fletcher from the Game \& Wildlife Conservation

254 Trust and the gamekeepers in Cairngorm National Park, Scotland.

255 We would like to express our gratitude to Robert B. Davis for correction of the English

256 language. Thanks for help in translating articles also goes to Mr. Roland Kralik.

257

258 REFERENCES

259

260

261

262

263

264

265

266

267

268

269

270

271

272

273

274

275

1. Borecha DE, Willebrand T, and Nielsen OK. 2017. Lek site defines annual spatial use of male Black Grouse (Tetrao tetrix). Ornis Fennica 94:150-160.

2. Budka M, Deoniziak K, Tumiel T, and Wozna JT. 2018. Vocal individuality in drumming in Great Spotted Woodpecker - a biological perspective and implications for conservation. PLOS ONE:13: e0191716.

3. Ciach M. 2015. Rapid decline of an isolated population of the black grouse Tetrao tetrix: the crisis at the southern limit of the range. European Journal of Wildlife Research 61:623-627. 10.1007/s10344-015-0923-7

4. Collins SA, and Goldsmith AR. 1998. Individual and species differences in quail calls (Coturnix c. japonica, c. c. coturnix and a hybrid). Ethology 104:977-990.

5. Cornec C, Hingrat Y, and Rybak F. 2014. Individual Signature in a Lekking Species: Visual and Acoustic Courtship Parameters May Help Discriminating Conspecifics in the Houbara Bustard. Ethology 120:726-737. 10.1111/eth.12244

6. Cramp S. 1983. Handbook of the birds of Europe, the Middle East and North Africa : the birds of the Western Palearctic. Vol. 3, Waders to gulls. Oxford: Oxford University Press. 
276

277

278

279

280

281

282

283

284

285

286

287

288

289

290

291

292

293

294

296

7. Fitch WT, and Hauser MD. 2003. Unpacking "Honesty": Vertebrate Vocal Production and the Evolution of Acoustic Signals. In: Simmons AM, Fay RR, and Popper AN, eds. Acoustic Communication. New York, NY: Springer New York, 65-137.

8. Formenti N, Vigano R, Bionda R, Ferrari N, Cerutti MC, R. P, and Lanfranchi P. 2012. Evaluation of the physiological stress response induced by winter sports in a black grouse (Tetrao tetrix) population from Lepontine Alps. 3rd annual ISWE meeting 2012. Vienna, Austria: Wiener Tierarztliche Monatsschrift. p 60-61.

9. Franceschi S, Nelli L, Pisani C, Franzoi A, Fattorini L, and Meriggi A. 2014. A Monte Carlo Appraisal of Plot and Distance Sampling for Surveys of Black Grouse and Rock Ptarmigan Populations in Alpine Protected Areas. Journal of Wildlife Management 78:359-368. 10.1002/jwmg.661

10. Guyomarc'h JC, Aupiais A, and Guyomarc'h C. 1998. Individual differences in the longdistance vocalizations used during pair bonding in European quail (Coturnix coturnix). Ethology Ecology \& Evolution 10:333-346. 10.1080/08927014.1998.9522847

11. Hale JA, Nelson DA, and Augustine JK. 2014. Are vocal signals used to recognize individuals during male-male competition in greater prairie-chickens (Tympanuchus cupido)? Behavioral Ecology and Sociobiology 68:1441-1449. 10.1007/s00265-014$1751-6$

12. Hancock M, Baines D, Gibbons D, Etheridge B, and Shepherd M. 1999. Status of male Black Grouse Tetrao tetrix in Britain in 1995-96. Bird Study 46:1-15.

$10.1080 / 00063659909461110$

PeerJ reviewing PDF | (2020:09:52869:2:0:NEW 21 Jun 2021) 
297

298

299

300

301

302

303

304

305

306

307

308

309

310

311

312

313

314

315

316

317

13. Hess JE, and Beck JL. 2012. Disturbance factors influencing greater sage-grouse lek abandonment in north-central Wyoming. Journal of Wildlife Management 76:1625-1634. 10.1002/jwmg.417

14. Charnov EL, Orians GH, and Hyatt K. 1976. Ecological implications of resource depression. American Naturalist 110:247-259. 10.1086/283062

15. Ingold P. 2005. Freizeitaktivitäten im Lebensraum der Alpentiere Konfliktbereiche zwischen Mensch und Tier ; mit einem Ratgeber für die Praxis.

16. Jankovska I, Bejcek V, Langrova I, Valek P, Vadlejch J, and Cadkova Z. 2012. Black grouse in Czech Republic and its parasites. Helminthologia 49:78-81. 10.2478/s11687012-0016-Z

17. Kasprzykowski Z. 2002. Decline of the black grouse Tetrao tetrix population in eastcentral Poland. Vogelwelt 123:253-258.

18. Koch RE, Krakauer AH, and Patricelli GL. 2015. Investigating female mate choice for mechanical sounds in the male Greater Sage-Grouse. Auk 132:349-358. 10.1642/auk-1463.1

19. Korpimaki E, Koivunen V, and Hakkarainen H. 1996. Microhabitat use and behavior of voles under weasel and raptor predation risk: Predator facilitation? Behavioral Ecology 7:30-34. 10.1093/beheco/7.1.30

20. Kurhinen J, Danilov P, Gromtsev A, Helle P, and Linden H. 2009. Patterns of black grouse, Tetrao tetrix distribution in northwestern Russia at the turn of the millennium. Folia Zoologica 58:168-172. 
318

319

320

321

322

323

324

325

326

327

328

329

330

331

332

333

334

335

336

337

338
21. Kvasnes MAJ, Storaas T, Pedersen HC, Bjork S, and Nilsen EB. 2010. Spatial dynamics of Norwegian tetraonid populations. Ecological Research 25:367-374. 10.1007/s11284009-0665-7

22. Laiolo P, Vogeli M, Serrano D, and Tella JL. 2007. Testing acoustic versus physical marking: two complementary methods for individual-based monitoring of elusive species. Journal of Avian Biology 38:672-681. 10.1111/j.2007.0908-8857.04006.x

23. Meinert U, and Bergmann HH. 1983. Vocal development during the juvenile period in the black grouse (Tetrao tetrix). Behaviour 85:242-259. 10.1163/156853983x00246

24. Mulhauser B, and Zimmermann J. 2003. Recognition of male Hazel Grouse Bonasa bonasia by their song: individualisation des mâles de gélinotte des bois Bonasa bonasia grâce à leur chant. Bulletin de la Société Neuchâteloise des Sciences Naturelles 2:107119.

25. Nichter AN, Lipp TW, and Gregory AJ. 2017. A possible impact of anthropogenic noise on male Lesser Prairie-chicken lek attendance in Kansas. Grouse News 54:6-9.

26. Pekkola M, Alatalo R, Poysa H, and Siitari H. 2014. Seasonal survival of young and adult black grouse females in boreal forests. European Journal of Wildlife Research 60:477488. $10.1007 / \mathrm{s} 10344-014-0809-0$

27. Policht R, Hart V, Goncharov D, Surovy P, Hanzal V, Cerveny J, and Burda H. 2019. Vocal recognition of a nest-predator in black grouse. Peerj 7:12. 10.7717/peerj.6533

28. Policht R, Kowalczyk A, Lukaszewicz E, and Hart V. 2020. Hissing of geese: caller identity encoded in a non-vocal acoustic signal. Peerj 8:18. 10.7717/peerj.10197 
339

340

341

342

343

344

345

346

347

348

349

350

351

352

353

354

355

356

357

358

359

29. Robisson P. 1992. Roles of pitch and duration in the disrimination of the mate's call in the king penguin Aptenodytes patagonicus. Bioacoustics 4:25-36.

$10.1080 / 09524622.1992 .9753202$

30. Segelbacher G, Hoglund J, and Storch I. 2003. From connectivity to isolation: genetic consequences of population fragmentation in capercaillie across Europe. Molecular Ecology 12:1773-1780. 10.1046/j.1365-294X.2003.01873.x

31. Segelbacher G, Strand TM, Quintela M, Axelsson T, Jansman HAH, Koelewijn HP, and Hoglund J. 2014. Analyses of historical and current populations of black grouse in Central Europe reveal strong effects of genetic drift and loss of genetic diversity. Conservation Genetics 15:1183-1195. 10.1007/s10592-014-0610-3

32. Sezer M, and Tekelioglu O. 2010. Variation in Advertisement Call Properties of the Japanese Quail. Pakistan Journal of Zoology 42:581-586.

33. Storch I. 2013. Human disturbance of grouse - why and when? Wildlife Biology 19:390403. $10.2981 / 13-006$

34. Summers RW, Green RE, Proctor R, Dugan D, Lambie D, Moncrieff R, Moss R, and Baines D. 2004. An experimental study of the effects of predation on the breeding productivity of capercaillie and black grouse. Journal of Applied Ecology 41:513-525. 10.1111/j.0021-8901.2004.00891.x

35. Tornberg R, Linden A, Byholm P, Ranta E, Valkama J, Helle P, and Linden H. 2013. Coupling in goshawk and grouse population dynamics in Finland. Oecologia 171:863872. $10.1007 / \mathrm{s} 00442-012-2448-\mathrm{z}$ 
360 36. Viterbi R, Imperio S, Alpe D, Bosser-peverelli V, and Provenzale A. 2015. Climatic

361

362

363

364

365

366

367

368

369 Control and Population Dynamics of Black Grouse (Tetrao tetrix) in the Western Italian Alps. Journal of Wildlife Management 79:156-166. 10.1002/jwmg.810

37. White PJC, Warren P, and Baines D. 2013. Forest expansion in Scotland and its potential effects on black grouse Tetrao tetrix conservation. Forest Ecology and Management 308:145-152. 10.1016/j.foreco.2013.07.038

38. Widen P, Andren H, Angelstam P, and Lindstrom E. 1987. The effect of prey vulnerability - goshawk predation and population fluctuations of small game. Oikos $49: 233-235.10 .2307 / 3566032$ 
Figure 1

Spectrogram: Representative hissing calls of two of the black grouse from Scotland $(a, b)$ and Finland $(c, d)$.

Each lettered panel refers to one individual bird.

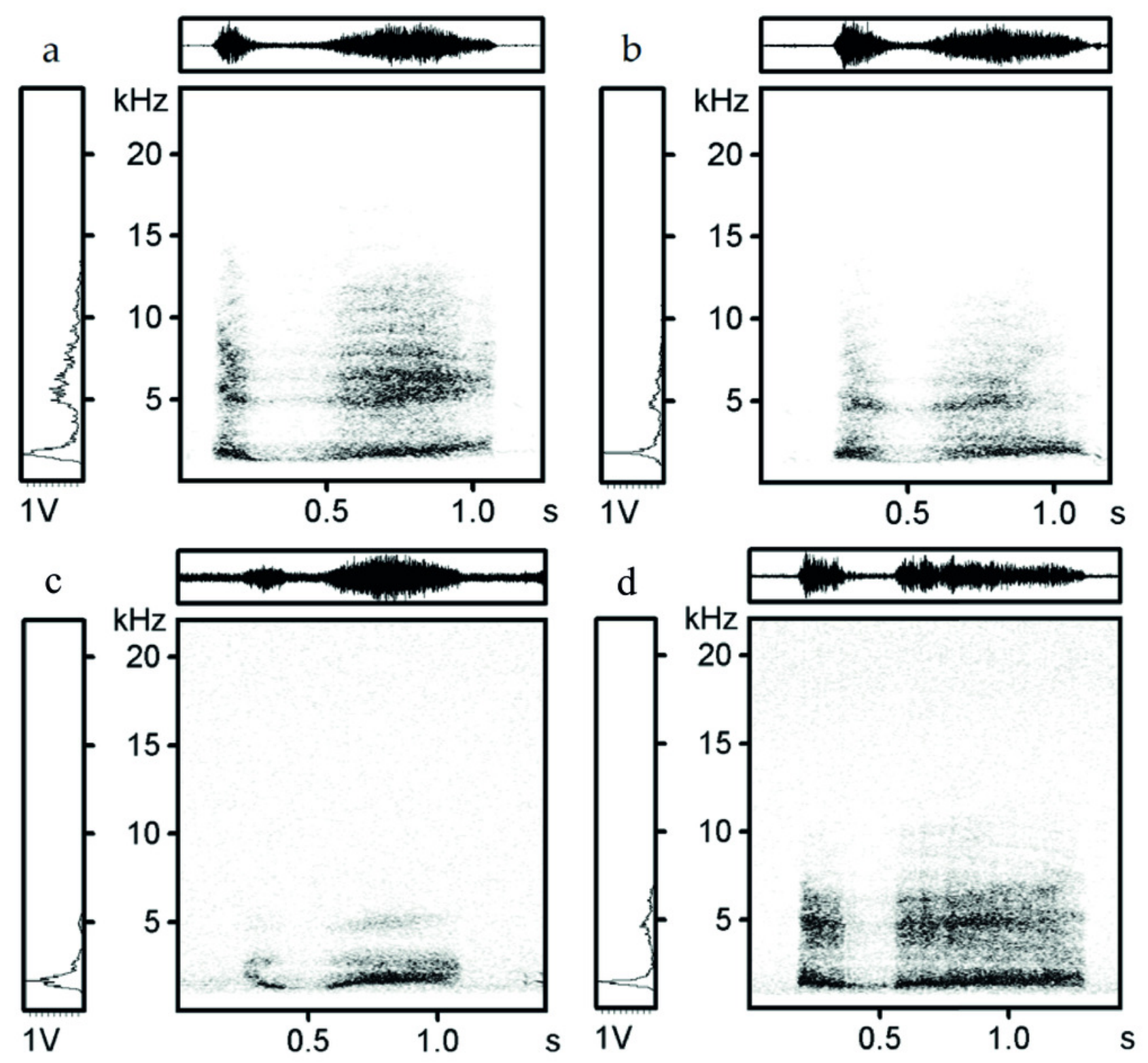


Figure 2

Spectrograms of 3 hissing calls of black grouse from one individual from Scotland $(a, b, c)$ and one individual from Finland $(d, e, f)$.

Each lettered panel refers to one hissing call.
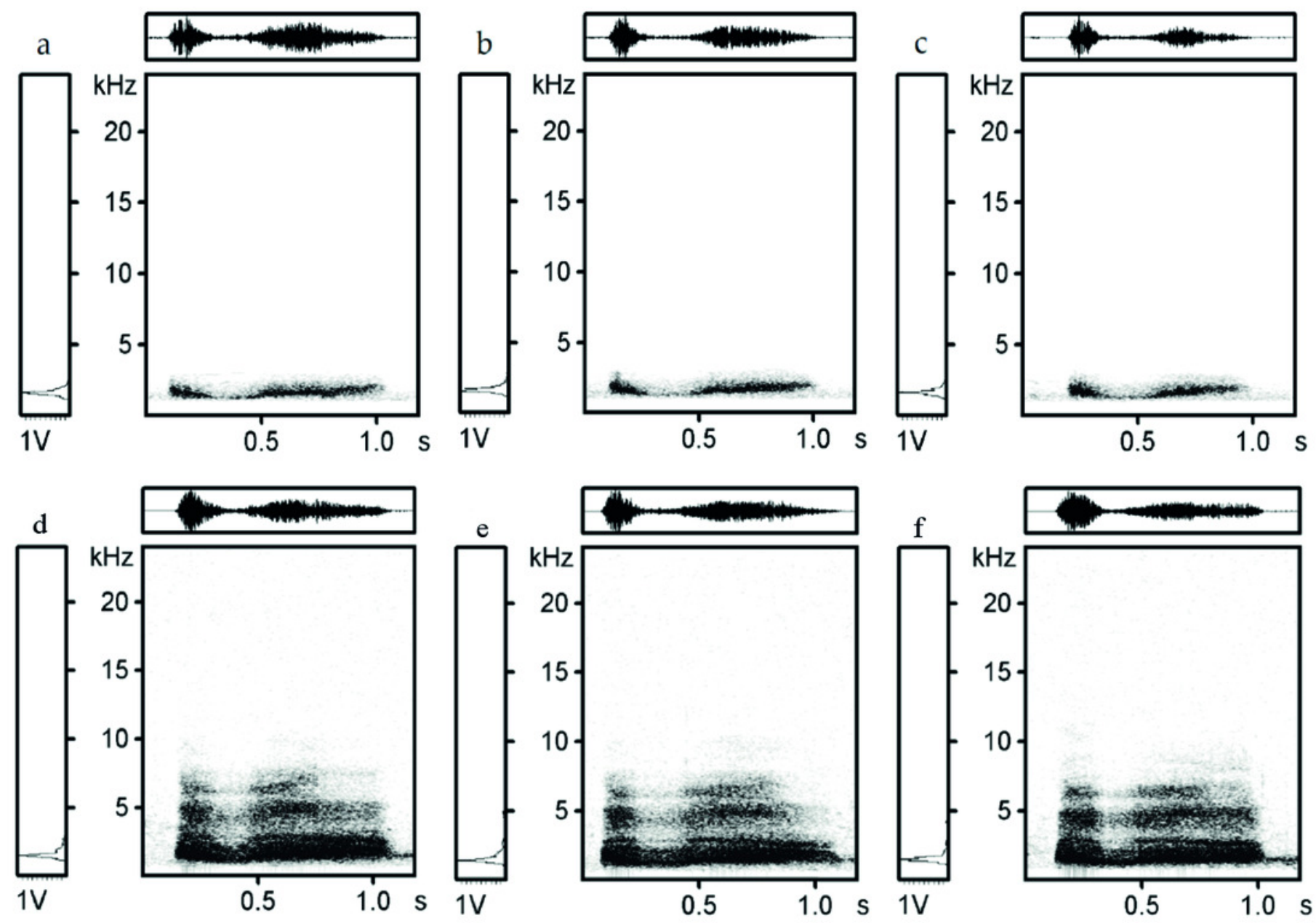
Figure 3

Scatter plot of hissing calls.

Numbers refer to individuals, pentagons represent group centroids. Discrimination function 1 represents Frequency 95\% and function 2 represents 1st Quartile Frequency .

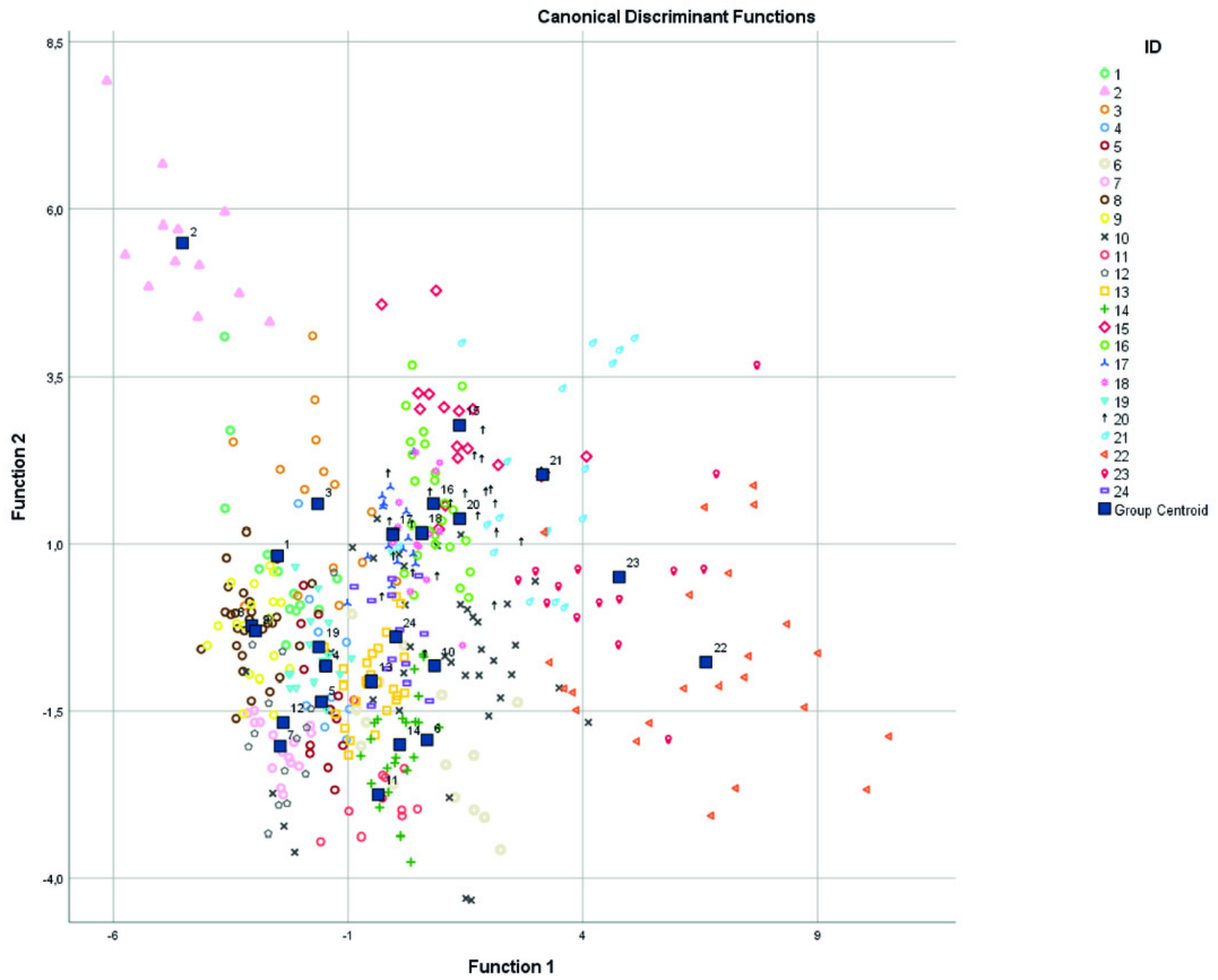




\section{Table $\mathbf{1}$ (on next page)}

Descriptions of acoustic parameters measured in Raven Pro 1.5 that entered statistical analysis. 13 parameters $(*)$ were included in resulting DFA model. 


\begin{tabular}{|c|c|c|}
\hline Acoustic parameter name & Abbreviations/Units & Description \\
\hline *1st Quartile Frequency & Q1 Freq $(\mathrm{Hz})$ & $\begin{array}{l}\text { The frequency that divides the selection into } \\
\text { two frequency intervals containing } 25 \% \text { and } \\
75 \% \text { of the energy in the signal. }\end{array}$ \\
\hline $\begin{array}{l}\text { * Relative 1st Quartile } \\
\text { Frequency }\end{array}$ & Q1 Freq Rel, & $\begin{array}{l}\text { The frequency that divides the selection into } \\
\text { two frequency intervals containing } 25 \% \text { and } \\
75 \% \text { of the energy in the signal relative to the } \\
\text { frequency range of the signal. }\end{array}$ \\
\hline *3rd Quartile Frequency & Q3 Freq $(\mathrm{Hz})$ & $\begin{array}{l}\text { The frequency that divides the selection into } \\
\text { two frequency intervals containing } 75 \% \text { and } \\
25 \% \text { of the energy in the signal. }\end{array}$ \\
\hline $\begin{array}{l}\text { Relative 3rd Quartile } \\
\text { Frequency }\end{array}$ & Q3 Freq Rel, & $\begin{array}{l}\text { The frequency that divides the selection into } \\
\text { two frequency intervals containing } 75 \% \text { and } \\
25 \% \text { of the energy in the signal relative to the } \\
\text { frequency range of the signal. }\end{array}$ \\
\hline 1st Quartile Time & Q1 Time (s) & $\begin{array}{l}\text { The time that divides the selection into two } \\
\text { time intervals containing } 25 \% \text { and } 75 \% \text { of the } \\
\text { energy in the selection. }\end{array}$ \\
\hline Relative 1st Quartile Time & Q1 Time Rel, & $\begin{array}{l}\text { The time that divides the selection into two } \\
\text { time intervals containing } 25 \% \text { and } 75 \% \text { of the } \\
\text { energy in the selection relative to signal } \\
\text { duration. }\end{array}$ \\
\hline Relative 3rd Quartile Time & Q3 Time Rel, & $\begin{array}{l}\text { The time that divides the selection into two } \\
\text { time intervals containing } 75 \% \text { and } 25 \% \text { of the } \\
\text { energy in the selection relative to signal } \\
\text { duration. }\end{array}$ \\
\hline *Aggregate Entropy & Agg Entropy (bits) & $\begin{array}{l}\text { The aggregate entropy measures the disorder } \\
\text { in a sound by analysing the energy } \\
\text { distribution. Higher entropy values } \\
\text { correspond to greater disorder in the sound } \\
\text { whereas a pure tone with energy only one } \\
\text { frequency bin would have zero entropy. It } \\
\text { corresponds to the overall disorder in the } \\
\text { sound. }\end{array}$ \\
\hline *Average Entropy & Avg Entropy (bits) & $\begin{array}{l}\text { This entropy is calculated by finding the } \\
\text { entropy for each frame in the signal and then } \\
\text { taking the average of these values. }\end{array}$ \\
\hline Bandwidth $90 \%$ & BW $90 \%(H z)$ & $\begin{array}{l}\text { The difference between the } 5 \% \text { and } 95 \% \\
\text { frequencies. }\end{array}$ \\
\hline
\end{tabular}




\begin{tabular}{|c|c|c|}
\hline Center Frequency & Center Freq $(\mathrm{Hz})$ & $\begin{array}{l}\text { The frequency that divides the selection into } \\
\text { two frequency intervals of equal energy. }\end{array}$ \\
\hline Center Time & Center Time (s) & $\begin{array}{l}\text { The point in time at which the selection is } \\
\text { divided into two time intervals of equal } \\
\text { energy. }\end{array}$ \\
\hline *Relative Center Time & Center Time Rel, & $\begin{array}{l}\text { The point in time at which the selection is } \\
\text { divided into two time intervals of equal } \\
\text { energy relative to the signal duration. }\end{array}$ \\
\hline *Call duration & Duration (s) & $\begin{array}{l}\text { The difference between Begin Time and End } \\
\text { Time for the selection. }\end{array}$ \\
\hline *Duration $90 \%$ & Dur $90 \%(s)$ & $\begin{array}{l}\text { The difference between the } 5 \% \text { and } 95 \% \\
\text { times. }\end{array}$ \\
\hline *Frequency $5 \%$ & Freq $5 \%(\mathrm{~Hz})$ & $\begin{array}{l}\text { The frequency that divides the selection into } \\
\text { two frequency intervals containing } 5 \% \text { and } \\
95 \% \text {. }\end{array}$ \\
\hline Relative Frequency 5\% & Freq 5\% Rel, & $\begin{array}{l}\text { The frequency that divides the selection into } \\
\text { two frequency intervals containing } 5 \% \text { and } \\
95 \% \text { relative to frequency range. }\end{array}$ \\
\hline *Frequency $95 \%$ & Freq 95\% (Hz) & $\begin{array}{l}\text { The frequency that divides the selection into } \\
\text { two frequency intervals containing } 95 \% \text { and } \\
5 \% \text {. }\end{array}$ \\
\hline Relative Frequency 95\% & Freq 95\% Rel, & $\begin{array}{l}\text { The frequency that divides the selection into } \\
\text { two frequency intervals containing } 95 \% \text { and } \\
5 \% \text { relative to frequency range. }\end{array}$ \\
\hline $\begin{array}{l}\text { *Inter-Quartile Range } \\
\text { Bandwidth }\end{array}$ & IQR BW (Hz) & $\begin{array}{l}\text { The difference between the 1st and 3rd } \\
\text { Quartile frequencies. }\end{array}$ \\
\hline $\begin{array}{l}\text { *IQR (Inter-quartile Range) } \\
\text { Duration }\end{array}$ & IQR Dur (s) & $\begin{array}{l}\text { The difference between the 1st and 3rd } \\
\text { Quartile Times. }\end{array}$ \\
\hline Max Entropy & Max Entropy (bits) & $\begin{array}{l}\text { Maximum entropy calculated from each } \\
\text { frame. }\end{array}$ \\
\hline Max Frequency & Max Freq $(\mathrm{Hz})$ & $\begin{array}{l}\text { The frequency at which Max Power occurs } \\
\text { within the selection. }\end{array}$ \\
\hline Max Time & Max Time (s) & $\begin{array}{l}\text { The first time in the selection at which a } \\
\text { spectrogram point with power equal to Max } \\
\text { Power/ Peak Power occurs. }\end{array}$ \\
\hline Min Entropy & Min Entropy (bits) & $\begin{array}{l}\text { The minimum entropy calculated for a } \\
\text { spectrogram slice within the selection bounds }\end{array}$ \\
\hline
\end{tabular}


Peak Time

*Time 5\%

Relative Time 5\%

Relative Time 95\%
Peak Time (s)

Time 5\% (s)

Time 5\% Rel,

Time 95\% Rel,
The first time in the selection at which a sample with amplitude equal to Peak Amplitude occurs.

The time that divides the signal into two time intervals containing 5\% and 95\%.

The time that divides the signal into two time intervals containing 5\% and $95 \%$ relative to signal duration.

The time that divides the signal into two time intervals containing $95 \%$ and $5 \%$ relative to signal duration.

1 


\section{Table 2 (on next page)}

Descriptive statistics and Potential for individual coding.

(DFA) 13 variables included in final DFA model (X). (SE) standard error of the mean. (KruskWallis) Kruskal-Wallis test after Bonferroni correction, $\left({ }^{*}\right) p<0.001$. (Mean CVw) within individual comparison. (CVa) between individual comparison. (PIC) Potential for Individual Coding. 


\begin{tabular}{|c|c|c|c|c|c|c|c|c|c|}
\hline Variable & DFA & Mean & Min & Max & SE & $\begin{array}{l}\text { Krusk- } \\
\text { Wallis }\end{array}$ & $\begin{array}{c}\text { Mean } \\
\text { CVw }\end{array}$ & CVa & PIC \\
\hline 1st Quartile Frequency & $x$ & 1444,3 & 0,9 & 3000,0 & 271,8 & $*$ & 38503,6 & 73887 & 1,919 \\
\hline Relative 1st Quartile Frequency & $x$ & 3,3 & 0,0 & 1500,0 & 62,4 & $*$ & 219,9 & 3896 & 17,714 \\
\hline 3rd Quartile Frequency & $x$ & 197,8 & 0,1 & 3027,8 & 436,6 & $*$ & 70423,4 & 190607 & 2,707 \\
\hline Relative 3rd Quartile Frequency & & 0,3 & 0,0 & 1,0 & 0,2 & $*$ & 0,0 & 0 & 1,960 \\
\hline 1st Quartile Time & & 1747,2 & 0,5 & 3562,5 & 367,6 & $*$ & 60556,2 & 135130 & 2,231 \\
\hline Relative 1st Quartile Time & & 2,4 & 0,1 & 1687,5 & 56,2 & $*$ & 229,5 & 3159 & 13,761 \\
\hline Relative 3rd Quartile Time & & 246,2 & 0,2 & 43525,0 & 1508,0 & $*$ & 216894,9 & 2274186 & 10,485 \\
\hline Aggregate Entropy & $x$ & 3,2 & 0,7 & 4,8 & 0,5 & $*$ & 0,2 & 0 & 1,846 \\
\hline Average Entropy & $x$ & 2,8 & 1,7 & 4,0 & 0,4 & $*$ & 0,1 & 0 & 1,869 \\
\hline Bandwidth $90 \%$ & & 839,2 & 187,5 & 2437,5 & 355,2 & $*$ & 69079,2 & 126142 & 1,826 \\
\hline Center Frequency & & 1589,0 & 468,8 & 3375,0 & 303,2 & $*$ & 45489,3 & 91910 & 2,020 \\
\hline Center Time & & 198,1 & 0,1 & 3028,1 & 436,6 & $*$ & 70428,0 & 190611 & 2,706 \\
\hline Relative Center Time & $x$ & 0,5 & 0,1 & 1,0 & 0,2 & $*$ & 0,0 & 0 & 2,470 \\
\hline Call Duration & $x$ & 1,0 & 0,2 & 1,9 & 0,2 & $*$ & 0,0 & 0 & 1,460 \\
\hline Duration $90 \%$ & $\mathrm{x}$ & 0,7 & 0,1 & 1,6 & 0,2 & $*$ & 0,0 & 0 & 1,657 \\
\hline Frequency $5 \%$ & $x$ & 1209,8 & 375,0 & 2250,0 & 249,9 & $*$ & 42818,7 & 62427 & 1,458 \\
\hline Relative Frequency 5\% & & 0,2 & 0,0 & 0,5 & 0,1 & $*$ & 0,0 & 0 & 1,303 \\
\hline Frequency $95 \%$ & & 2049,0 & 1125,0 & 4125,0 & 432,2 & $*$ & 84005,1 & 186777 & 2,223 \\
\hline Relative Frequency 95\% & & 0,7 & 0,3 & 1,0 & 0,1 & $*$ & 0,0 & 0 & 1,823 \\
\hline Inter-Quartile Range & $x$ & 301,8 & 86,1 & 1218,8 & 188,9 & $*$ & 17712,6 & 35694 & 2,015 \\
\hline IQR (Inter-quartile Range) Duration & $x$ & 0,4 & 0,0 & 1,2 & 0,1 & $*$ & 0,0 & 0 & 2,301 \\
\hline
\end{tabular}




\begin{tabular}{|c|c|c|c|c|c|c|c|c|c|}
\hline Max Entropy & & 3,9 & 2,9 & 4,9 & 0,3 & $*$ & 0,0 & 0 & 2,044 \\
\hline Max Frequency & & 1572,4 & 468,8 & 3468,8 & 336,3 & $*$ & 58737,8 & 113076 & 1,925 \\
\hline Max Time & & 197,9 & 0,1 & 3027,5 & 436,6 & $*$ & 70409,4 & 190584 & 2,707 \\
\hline Min Entropy & & 1,6 & 0,1 & 2,9 & 0,4 & $*$ & 0,1 & 0 & 1,685 \\
\hline Peak Time & & 197,9 & 0,1 & 3027,5 & 436,6 & $*$ & 70409,3 & 190583 & 2,707 \\
\hline Time 5\% & $\mathrm{x}$ & 197,9 & 0,0 & 3027,5 & 436,5 & $*$ & 70738,2 & 190565 & 2,694 \\
\hline Relative Time 5\% & & 0,1 & 0,0 & 0,4 & 0,0 & $*$ & 0,0 & 0 & 2,247 \\
\hline Relative Time 95\% & & 0,8 & 0,6 & 1,0 & 0,1 & * & 0,0 & 0 & 2,143 \\
\hline
\end{tabular}

1 